\title{
Whole Brain Radiotherapy Plus Conventional Boost in Non-Small Cell Lung Cancer Patients with Brain Metastasis: A Retrospective Analysis of Overall Survival
}

\author{
Mustafa KANDAZ1', Ozan Cem GULER ${ }^{1}$, Ugur YAZAR², Emine CANYILMAZ¹, Adnan YONEY ${ }^{1}$ \\ ${ }^{1}$ Karadeniz Technical University, Faculty of Medicine, Department of Radiation Oncology, Trabzon, Turkey \\ ${ }^{2}$ Karadeniz Technical University, Faculty of Medicine, Department of Neurosurgery, Trabzon, Turkey \\ Corresponding author: Mustafa KANDAZ mkandaz61@gmail.com
}

\section{ABSTRACT}

\begin{abstract}
AIM: To evaluate the clinical characteristics and treatment outcomes of non-small cell lung cancer (NSCLC) patients with brain metastasis, who were treated by whole brain radiotherapy with a conventional boost at a single institution.

MATERIAL and METHODS: A total of 296 patients diagnosed with NSCLC with brain metastasis and referred to our clinic for radiotherapy between 2000 and 2017 were included in this retrospective study.

RESULTS: The median age was $60.8 \pm 12.1$ years, with a range of $21-85$ years. The estimated median survival time for all patients was $7.81 \pm 0.66$ months $(95 \% \mathrm{Cl}: 6.52-9.11)$. The one-year survival, two-year survival and three-year survival rates were $18.8 \%$, $5.8 \%$ and $2.9 \%$, respectively. The median survival of patients with solitary brain metastasis who received 45 Gy radiotherapy was $14.70 \pm 2.80$ months (95\% Cl: 9.20-20.20). These patients had 6 and 12 months survival rates of $65.4 \%$ and $42.6 \%$, respectively. The median survival time of patients with solitary brain metastasis who received $>45$ Gy radiotherapywas $13.86 \pm 2.56$ months (95\% Cl: 8.08-18.02). These patients had 6 and 12 months survival rates of $66.2 \%$ and $27.2 \%$, respectively. There was no significant difference between the two groups ( $p=0.321$ ). The median survival duration of patients under 65 years was $9.65 \pm 1.02$ months. The median survival time of patients aged 65 years and overwas $5.15 \pm 0.51$ months. There was a statistically significant difference in the median survival rates between the groups $(p<0.001)$.
\end{abstract}

CONCLUSION: Patients with solitary metastasis or single metastases tolerated whole brain radiotherapy with a conventional boost. Although the overall survival rates were numerically better in the high dose RT group, the difference was not statistically significant. Prospective studies with a larger sample size are needed to consolidate our results.

KEYWORDS: Non-small cell lung cancer, Brain metastases, Radiotherapy

\section{INTRODUCTION}

$\mathrm{B}$ rain metastases are the most common type of intracranial tumours (8 times more common than primary brain tumours) and are significantly relevant in patients with cancer. Brain metastases are a widespread complication of systemic cancers and occur in one out of three cancer patients
(20). Probably due to improvements in overall survival, the incidence of brain metastasis is on the rise. Primary cancers such as breast cancer, lung cancer, melanoma and renal cell carcinoma are most likely to metastasise to the brain.

Lung cancer is a significant source of brain metastasis. Approximately $34 \%-64 \%$ of patients with non-small cell lung
Mustafa KANDAZ (D): 0000-0003-1106-6227 Ozan Cem GULER (1D : 0000-0001-6908-3412 Ugur YAZAR (D) : 0000-0003-4749-113X
Emine CANYILMAZ (1) : 0000-0002-0736-1293

Adnan YONEY (iD : 0000-0003-4598-8836 
cancer (NSCLC) develop brain metastasis. Of these patients, $10 \%-20 \%$ present with brain metastases at the time of diagnosis $(7,12)$.

The term solitary brain metastasis describes the only known metastasis of a tumour in the whole body that localises in the central nervous system. A single brain metastasis is defined as a single cerebral metastasis with additional metastases in other organ systems (25).

Treatment of brain metastases is a multidisciplinary approach. Treatment options include surgery, radiotherapy and chemotherapy. Therefore, close cooperation is needed between medical oncologists, neurosurgeons and radiation oncologists. Surgery plays a major role in the local control of metastatic disease. It is the most commonly accepted treatment option for local control in cases of oligometastases. The term 'oligometastasis' describes the presence of 3 or more metastatic tumours at any site. After metastasectomy, adjuvant treatment options include whole brain radiotherapy (WBRT), local radiotherapy (RT) to the tumour bed or observation with best supportive care. Traditionally, WBRT has been commonly performed, with a typical dose of 30 Gy in 10 fractions. Regardless, since prolonged local control is unusual, WBRT mostly has a palliative effect, including in patients with multiple brain metastases. However, dose escalation approaches based on standard radiation therapy techniques have raised concerns about quality of life and neurocognitive impairment, thereby restricting this field of research. Simultaneous irradiation of the brain and metastases at various doses may be useful in terms of local control and overall survival (OS) in selected patients (5). With advances in imaging and techniques for stereotactic radiosurgery (SRS), radiation metastasectomy is becoming more common (3).

In this study, we aimed to investigate the effect of dose escalation on the OS in NSCLC patients with brain metastasis.

\section{MATERIAL and METHODS}

This retrospective clinical study was conducted with permission from the Ethics Committee at the Karadeniz Technical University Faculty of Medicine (2017-188). A total of 296 NSCLC patients with brain metastasis recorded between 2000 and 2017 were included in the study. Brain metastasis was diagnosed radiologically via magnetic resonance imaging (MRI) or computerised tomography (CT). Patient age, sex, radiotherapy dose, number of metastatic masses, distant metastases and surgeries were recorded.

\section{Treatment}

All patients were positioned supine in a custom-made mask and received a CT simulation scan of the entire cranium region. All CT scans had 2.5-mm slice thickness. Three-dimensional conformal radiotherapy (3D-CRT) was performed at fractions of 3 Gy daily for a total of 30 to 45 Gy and delivered using 6-18 MV photons. Given the retrospective nature of the study, no randomisation was performed. Clinicians prescribed doses based on the choice of each patient and performance status. The clinical target volume 1 (CTVwb): whole brain, gross target volume 2 (GTVm): metastatic mass or clinical target volume 2 (CTVm): mass bed (MRG is determined by fusion). The planned target volume 1 (PTVwb) was forged with $0.5 \mathrm{~cm}$ margins and given up to the CTVwb. The planned target volume 2 (PTVm) was forged with $1.5 \mathrm{~cm}$ margins and given up to the GTVm or CTVm. Ten fractions each of 3 Gy for a total of 30 Gy were given up to the PTV1. Five fractions each of 3 Gy for a total of 15 Gy were given up to the PTV2. Therefore, total tumour dose totalled 45 Gy. A daily dose of dexamethasone (4-16 mg) was administered orally during radiotherapy.

\section{Follow-up}

After 2 months of RT, all patients were clinically examined. Complete blood test and MRI or CT controls were performed. OS was described as the time between diagnosis and the last control or death date.

\section{Statistical Analysis}

Statistical analysis was performed using the SPSS software (SPSS for Windows, Version 16.0. Chicago, USA). The OS was estimated using the Kaplan-Meier method. The difference in survival rates between the groups was examined using the logrank test. All results were considered statistically significant at a $p<0.05$.

\section{RESULTS}

Of the 296 patients included in the study, 228 (77\%) were men and $68(23 \%)$ were women. The median age was 61 years (range: $21-87$ years). Overall, $172(58 \%)$ patients were aged 64 years or under, while $124(42 \%)$ were aged 65 years or over. The distribution by number of metastasis in patients was as follows: 61 patients $(21 \%)$ had solitary brain metastasis, 46 patients (15\%) had single brain metastasis, 52 patients (18\%) had two-mass brain metastasis (24 patients with only brain metastasis and 28 patients with two-mass brain metastasis plus other metastases) and 137 patients (46\%) had multiple brain metastases. In total, 26 patients $(8 \%)$ were operated for solitary brain metastasis. Patient grouping is addressed in Table 1.

\section{Survival}

As of December 2017, the median follow-up period was 7 months (range: 1-57 months). For the entire cohort, the median OS time was $7.81 \pm 0.66$ months (95\% Cl: 6.52-9.11) and the 1-year, 2-year and 3-year survival rates were $18.8 \%, 5.8 \%$ and $2.9 \%$, respectively.

The median OS time for patients with solitary brain metastasis who received 30 Gy radiotherapy (Group I) was $10.33 \pm$ 1.95 months (95\% Cl: 6.28-13.96). Their 1-year and 2-year survival rates were $41 \%$ and $7.8 \%$, respectively. No patient in Group I was alive after 3 years. For patients with solitary brain metastasis who received 45 Gy radiotherapy (Group II), the median OS time was $13.24 \pm 2.47$ months (95\% Cl: $8.16-$ 17.83). The 1-year, 2-year and 3-year survival rates for Group II patients were $38.5 \%, 19.8 \%$ and $9.9 \%$, respectively. Although the OS time was higher in the 45 Gy group, the difference was not statistically significant $(p=0.504)$. 
The median OS duration of patients with single brain metastasis who received 30 Gy radiotherapy (Group III) was $6.29 \pm 0.93$ months (95\% Cl: 4.43-8.09). Their 1-year and 2 -year survival rates were $16 \%$ and $8 \%$, respectively. No patient in Group III was alive after 3 years. For patients with single brain metastasis who received 45 Gy radiotherapy (Group IV), the median OS time was $7.40 \pm 0.83$ months $(95 \%$ Cl: 5.76-9.04). The 1-year, 2-year and 3-year survival rates for Group III patients were $19.1 \%, 4.8 \%$ and $3.6 \%$, respectively. There was no statistically significant difference between the two groups $(p=0.301)$.

In patients with two-mass brain metastasis who received 30 Gy radiotherapy (Group V), median OS time was $9.77 \pm 2.10$ months (95\% Cl: 5.64-13.90). Their 1-year and 2-year survival rates were $24.8 \%$ and $9.3 \%$, respectively. No patient in Group $\mathrm{V}$ was alive after 3 years. In patients with two-mass brain metastasis plus other metastasis (Group $\mathrm{VI}$ ) who received 30 Gy radiotherapy, median OS time was $6.82 \pm 1.19$ months
(95\% Cl: 4.49-9.16). The 1-year, 2-year and 3-year survival rates for Group VI were $20.5 \%$ and $6.8 \%$, respectively. No patient in Group VI was alive after 3 years.

The median OS duration of patients with multiple brain metastasis who received 30 Gy radiotherapy (Group VII) was $5.52 \pm 0.68$ months $(95 \% \mathrm{Cl}: 4.19-6.86)$. Their 1-year and 2 -year survival rates were $8.3 \%$ and $4.1 \%$, respectively. No patient in Group VII was alive after 3 years (Table I). A statistically significant difference was noted in the median survival rates among the seven groups $(p=0.002)$ (Table II).

After analysing Group I patients based on surgery and dose of radiotherapy, the median OS time for the WBRT $(n=15)$, surgery + WBRT $(n=10)$, WBRT + conventional boost $(n=20)$ and surgery + WBRT + conventional boost $(n=16)$ cohorts was $9,12,14$ and 13 months, respectively $(p=0.504)$. The median OS time for patients with solitary brain metastasis who received 30 Gy radiotherapy (Group la) was $9.90 \pm 2.48$

Table I: Patient Groups

\begin{tabular}{lcccc}
\hline Groups & $\mathbf{n}(\%)$ & RT Dose & Brain Metastasis & Distant Metastasis \\
\hline Group I & $25(9)$ & 30 Gy & Single & None \\
\hline Group II & $36(12)$ & 45 Gy & Single & None \\
\hline Group III & $27(9)$ & 30 Gy & Single & Present \\
\hline Group IV & $19(6)$ & 45 Gy & Single & Present \\
\hline Group V & $24(8)$ & 30 Gy & Two & None \\
\hline Group VI & $28(10)$ & 30 Gy & Two & Present \\
\hline Group VII & $137(46)$ & 30 Gy & Multiple & Present
\end{tabular}

RT: Radiotherapy.

Table II: Survival Analysis in all Patients

\begin{tabular}{|c|c|c|c|c|c|c|c|}
\hline Groups & n (\%) & RT Dose & $\begin{array}{l}\text { Overall Survival* } \\
(95 \% \mathrm{Cl})\end{array}$ & $\begin{array}{c}\text { Survival Rate } \\
\text { 1-year (\%) }\end{array}$ & $\begin{array}{c}\text { Survival Rate } \\
\text { 2-year (\%) }\end{array}$ & $\begin{array}{c}\text { Survival Rate } \\
\text { 3-year (\%) }\end{array}$ & $\mathbf{p}$ \\
\hline Group I & $25(9)$ & 30 Gy & $\begin{array}{l}10.33 \pm 1.95 \\
(6.28-13.96)\end{array}$ & 41.0 & 7.8 & - & \multirow{2}{*}{0.504} \\
\hline Group II & 36 (12) & 45 Gy & $\begin{array}{l}13.24 \pm 2.47 \\
(8.16-17.83)\end{array}$ & 38.5 & 19.8 & 9.9 & \\
\hline Group IV & $19(6)$ & 45 Gy & $\begin{array}{l}7.40 \pm 0.83 \\
(5.76-9.04)\end{array}$ & 19.1 & 4.8 & 3.6 & 0.301 \\
\hline Group V & $24(8)$ & 30 Gy & $\begin{array}{c}9.77 \pm 2.10 \\
(5.64-13.90)\end{array}$ & 24.8 & 9.3 & - & 0.002 \\
\hline
\end{tabular}

RT: Radiotherapy, * Overall survival is given in months. 
months (95\% Cl: 5.03-14.76). The 6-month and 12-month survival rates for Group la patients were $45.3 \%$ and $37.7 \%$, respectively. For patients with solitary brain metastasis who received surgery +30 Gy radiotherapy (Group lb), the median OS time was $12.33 \pm 3.76$ months (95\% Cl: 4.95-19.71). The 6-month and 12-month survival rates for Group lb patients were $66.7 \%$ and $50 \%$, respectively. There was no statistically significant difference between the two groups $(p=0.294)$.

In patients with solitary brain metastasis who received 45 Gy radiotherapy (Group Ila), the median OS time was $14.70 \pm 2.80$ months (95\% Cl: 9.20-20.20). The 6-month and 12-month survival rates for Group lla patients were $65.4 \%$ and $42.6 \%$, respectively. For patients with solitary brain metastasis who received surgery +45 Gy radiotherapy (Group Ilb), the median OS time was $13.86 \pm 2.56$ months (95\% Cl: 8.08-18.02). The 6-month and 12-month survival rates for Group Ilb patients were $66.2 \%$ and $27.2 \%$, respectively. There was no statistically significant difference between the two groups $(p=$ 0.321) (Table III) (Figure 1).

The age-based analysis revealed that the median survival duration for patients under 65 years was $9.65 \pm 1.02$ months (95\% Cl: $7.64-11.67)$, and $5.15 \pm 0.51$ months (95\% Cl: $4.15-$ 6.15) for patients of 65 years or over. There was a statistically significant difference in the median survival time between the groups $(p<0.001)$. With regards to surgery, the median survival duration for patients under 65 years was $9.59 \pm 1.11$ months (95\% Cl: $7.40-11.78)$ and $5.03 \pm 0.51$ months (95\% Cl: $4.02-$ $6.04)$ for patients 65 years or over. There was a statistically significant difference in median survival duration between the groups $(p<0.001)$. With regards to surgery, the median survival duration for patients under 65 years was $9.64 \pm 1.49$ months (95\% Cl: 6.71-12.57), and $6.74 \pm 2.39$ months $(95 \%$

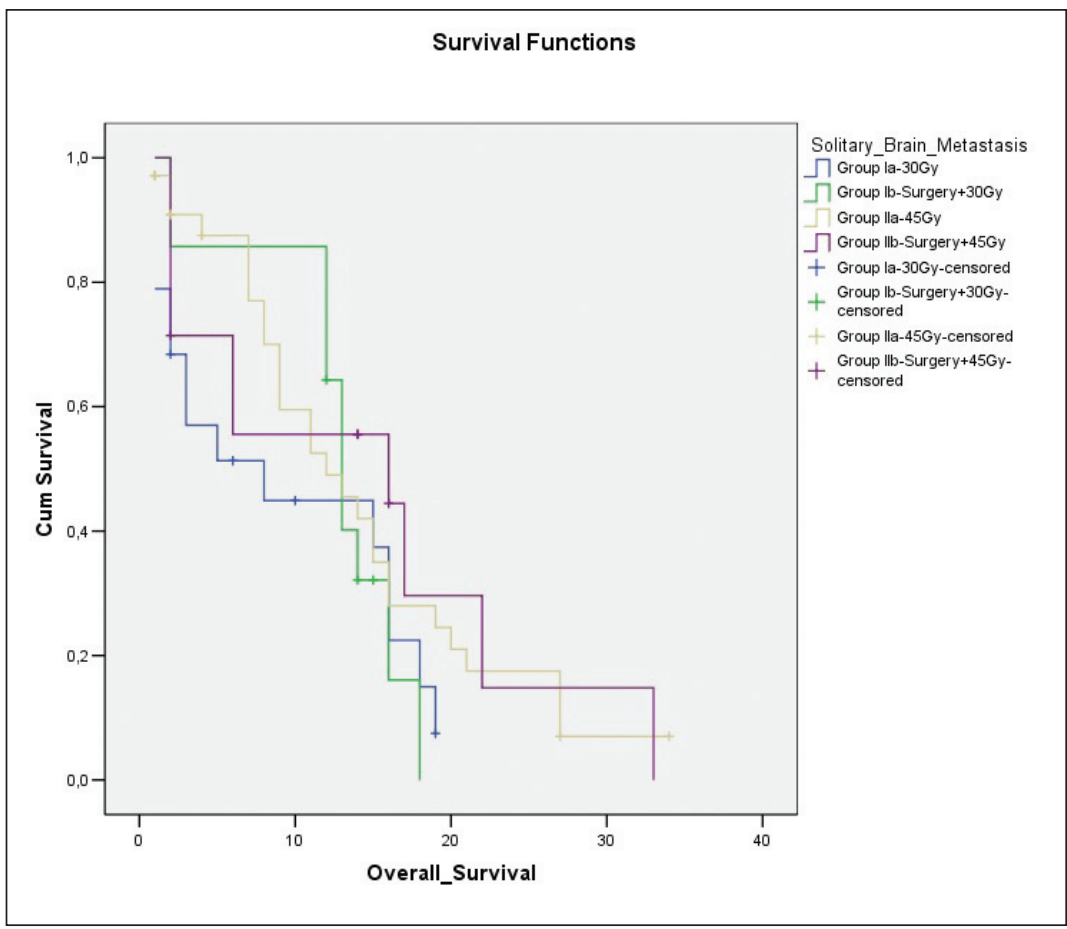

Figure 1: Survival analysis in patients with solitary brain metastasis.

Table III: Survival Analysis in Patients with Solitary Brain Metastasis

\begin{tabular}{|c|c|c|c|c|c|c|}
\hline & Treatment & n (\%) & $\begin{array}{c}\text { OS* }^{*} \\
(95 \% \mathrm{Cl})\end{array}$ & $\begin{array}{l}\text { Survival Rate } \\
6 \text { months (\%) }\end{array}$ & $\begin{array}{l}\text { Survival Rate } \\
12 \text { months (\%) }\end{array}$ & $\mathbf{p}$ \\
\hline Group la & 30Gy & $15(4)$ & $\begin{array}{c}9.90 \pm 2.48 \\
(5.03-14.76)\end{array}$ & 45.3 & 37.7 & \multirow{2}{*}{0.294} \\
\hline Group Ib & Surgery+30Gy & $10(3)$ & $\begin{array}{l}12.33 \pm 3.76 \\
(4.95-19.71)\end{array}$ & 66.7 & 50 & \\
\hline Group IIb & Surgery+45Gy & $16(5)$ & $\begin{array}{l}13.86 \pm 2.56 \\
(8.08-18.02)\end{array}$ & 66.2 & 27.2 & 0.321 \\
\hline
\end{tabular}

\footnotetext{
* Overall survival is given in months.
} 
Cl: 2.05-11.43) for patients of 65 years or over. There was no statistically significant difference between groups in median survival duration $(p=0.387)$.

\section{Toxicity}

During the treatment course, dexamethasone was administered to relieve symptoms. No patient experienced grade 3-4 skin toxicity and no patient died because of surgery or RT.

\section{DISCUSSION}

Brain metastasis is the most common form of intracranial tumour, with high mortality and morbidity rates. It has a high incidence rate in Turkey and the Eastern Black Sea region and it is an important cause of cancer mortality. On average, between 750 and 850 new cancer cases are reported at our clinic every year. Of these cases, between 100 and 150 cases present with brain metastasis. The most common primary causes of brain metastasis reported in our clinic are NSCLC (40-60\%), small cell lung cancer (15-20\%) and breast cancer $(10-15 \%)$.

Administration and dosage of WBRT varies from clinic to clinic. The applied dose and fraction ranges from 30 Gy (3 Gy daily) to 40 Gy (2 Gy daily) and to 50 Gy (2 Gy daily) (23). However, no difference in OS was observed among the various dosages and fractions studied $(14,26)$. Consequently, there is no consensus on the optimal radiation dose for patients with brain metastasis (13). In our clinic, 10 fractions each of 3 Gy for a total of 30 Gy were administered for the WBRT and 5 fractions each of 3 Gy for a total 15 Gy were administered to the mass for a total tumour dose of $45 \mathrm{~Gy}$.

The mean survival duration for a patient with untreated brain metastasis is 1-3 months (1). In a study by Harputluoglu et al., the median survival duration for NSCLC patients with brain metastasis was 7.2 months and the 1-year survival rate was $20.7 \%$ (10). In a study by Sperduto et al., it was shown that the median survival is 7.00 months (range: 6.53-7.50) (24). In a study by Lutterbach et al., it was shown that the median survival is 3.4 months (13). In our study, the median survival was $7.81 \pm 0.66$ months. In accordance with the literature, the 1 -year, 2-year and 3-year OS rates were 18.8\%, 5.8\% and $2.9 \%$, respectively.

Despite numerous studies designed to improve treatment outcomes, the median survival duration remains between 3 and 6 months $(6,18)$. However, no difference in OS was observed among the various dosages and fraction schemes studied.

A great number of studies indicate that patients with a single brain metastasis have a better chance of survival than those with multiple brain metastases $(16,19,24)$. Nevertheless, some studies show that neither the number of brain metastases nor the intracranial site of brain metastases were significant factors for prognosis (8). The Radiation Therapy Oncology Group study 9508 comparing number of metastases (one to two to three) later provided prospective evidence that the number of brain metastases was prognostic. A survival benefit was confirmed for patients with a single brain metastasis when treated with WBRT plus SRS compared to WBRT alone.
However, no survival benefit was seen in patients with two or three brain metastases (2). Comparison among groups showed a statistically significant difference in median survival times. Similar to previous studies, we found that median survival times were better in patients with solitary brain metastasis $(p=0.002)$.

In a prospective study by Ferro et al., IMRT-SIB-WBRT was feasible and safe in a Phase I clinical trial using 30 Gy WBRT with a boost up to $50 \mathrm{~Gy}$ (7). The median OS time was 9 months and the 1-year survival rate was $50 \%$ for patients treated at doses of 35 Gy and 40 Gy. In patients treated at higher doses, the median OS time was 12 months and the 1-year survival rate was $56.1 \%$. Nichol et al. treated patients who had between 1 and 10 metastases with a similar treatment [volumetric modulated arc therapy (VMRT) SIB], delivering 20 Gy to the whole brain and 47.5 Gy to the metastases in 5 daily fractions. The authors observed a median survival duration of 10.1 months (15). We applied WBRT plus a conventional boost and found a median survival duration of 13.3 months in solitary metastases and 7.4 months in single metastases.

Several retrospective studies administered adjuvant WBRT after resection. Some of these studies suggested a reduction in intracranial relapses and improvements in survival for some patients $(4,22)$. However, in most studies, no improvement in survival was observed $(11,21)$. In a randomised study, the median survival duration was approximately 10 months, with no statistically significant difference between the two groups (17). In a series conducted by Giubilei et al., 30 patients were treated by hypofractionated stereotactic radiotherapy (HSRT) combined with WBRT (30 Gy in 10 fractions). The total doses for HSRT were 18 Gy and 32 Gy. The median survival duration for the overall group of patients after combined treatment was 9.15 months (9). In our study, the median survival duration was 12 months in patients who received surgery + WBRT $(n=10)$ and 13 months in patients who received surgery + WBRT + conventional boost $(n=16)$. These results are comparable to reports from some previous studies. However, there was no statistically significant difference between the groups.

Our study has various limitations. Primarily, it is a retrospective study conducted at a single centre. Therefore, results should be interpreted with caution. In addition, the limited sample size makes it difficult to achieve statistical significance in the subgroup analysis, thereby limiting the power of any conclusions. Also, this retrospective study includes patients treated across a 7 -year period. During this period, RT techniques were improved which may have resulted in a selection bias. Furthermore, we only investigated the RT dosage, but comorbidities may also play an important role in patient selection. Finally, we did not analyse the quality of life and neurocognitive impairment.

\section{CONCLUSION}

Our patients with solitary and single metastasis tolerated WBRT plus a conventional boost. Although OS rates were numerically better in high dose RT group, the results were not statistically significant. Larger prospective studies are needed to support our findings. 


\section{REFERENCES}

1. Ali A, Goffin JR, Arnold A, Ellis PM: Survival of patients with non-small-cell lung cancer after a diagnosis of brain metastases. Curr Oncol 20:300-306, 2013

2. Andrews DW, Scott CB, Sperduto PW, Flanders AE, Gaspar LE, Schell MC, Werner-Wasik M, Demas W, Ryu J, Bahary JP, Souhami L, Rotman M, Mehta MP, Curran WJ Jr: Whole brain radiation therapy with or without stereotactic radiosurgery boost for patients with one to three brain metastases: Phase III results of the RTOG 9508 randomised trial. Lancet 363:16651672, 2004

3. Aoyama H, Tago M, Kato N, Toyoda T, Kenjyo M, Hirota S, Shioura H, Inomata T, Kunieda E, Hayakawa K, Nakagawa K, Kobashi G, Shirato H: Neurocognitive function of patients with brain metastasis who received either whole brain radiotherapy plus stereotactic radiosurgery or radiosurgery alone. Int Radiat Oncol Biol Phys 68(5):1388-1395, 2007

4. Armstrong JG, Wronski M, Galicich J, Arbit E, Leibel SA, Burt M: Postoperative radiation for lung cancer metastatic to the brain. J Clin Oncol 12:2340-2344, 1994

5. Brown P, Asher A, Ballman K, Farace E, Cerhan J, Anderson SK, Carrero X, Barker F, Deming II R, Burri S, Ménard C, Chung C, Stieber V, Pollock B, Galanis E, Buckner J, Jaeckle K: BMET-05 NCCTG N0574 (ALLIANCE): A Phase III randomızed trial of whole brain radiation therapy (WBRT) in addition to radiosurgery (SRS) in patients with 1 to 3 brain metastases. Neuro Oncol 17(5):45-46, 2015

6. Dirier A, Karadayi B: Comparison of two different radiotherapy schedules in lung cancer patients with brain metastasis. Dicle Tıp Dergisi 33(3):134-138, 2006

7. Ferro M, Chiesa S, Macchia G, Cilla S, Bertini F, Frezza G, Farioli A, Cammelli S, Balducci M, laniro A, Angelini AL, Compagnone G, Valentini V, Deodato F, Morganti AG: Intensity modulated radiation therapy with simultaneous integrated boost in patients with brain oligometastases: A phase 1 study (ISIDE-BM-1). Int J Radiat Oncol Biol Phys 97(1):82-90, 2017

8. Fleckenstein $\mathrm{K}$, Hof $\mathrm{H}$, Lohr F, Wenz F, Wannenmacher M: Prognostic factors for brain metastases after whole brain radiotherapy. Strahlenther Onkol 5:268-273, 2004

9. Giubilei C, Ingrosso G, D'Andrea M, Benassi M, Santoni R: Hypofractionated stereotactic radiotherapy in combination with whole brain radiotherapy for brain metastases. J Neurooncol 91:207-212, 2009

10. Harputluoglu H, Kaplan N, Dikilitas M, Yagar Y: Factors affecting survival in non-small cell lung cancer patients with brain metastasis. International Journal of Hematology and Oncology 26(4):199-205, 2016

11. Kocher M, Soffietti R, Abacioglu U, Villà S, Fauchon F, Baumert BG, Fariselli L, Tzuk-Shina T, Kortmann RD, Carrie C, Ben Hassel M, Kouri M, Valeinis E, van den Berge D, Collette $\mathrm{S}$, Collette L, Mueller RP: Adjuvant whole-brain radiotherapy versus observation after radiosurgery or surgical resection of one to three cerebral metastases: Results of the EORTC 22952-26001 study. J Clin Oncol 29:134-141, 2011

12. Lind JS, Lagerwaard FJ, Smit EF, Postmus PE, Slotman BJ, Senan S: Time for reappraisal of extracranial treatment options? Synchronous brain metastases from nonsmall cell lung cancer. Cancer 117:597-605, 2011
13. Lutterbach J, Bartelt S, Ostertag C: Long-term survival in patients with brain metastases. J Cancer Res Clin Oncol 128:417-425, 2002

14. Murray KJ, Scott C, Greenberg HM, Emami B, Seider M, Vora NL, Olson C, Whitton A, Movsas B, Curran W: A randomized phase III study of accelerated hyperfractionation versus standard in patients with unresected brain metastasis: A report of RTOG 9104. Int J Radiat Oncol Biol Phys 39:571574, 1997

15. Nichol A, Ma R, Hsu F, Gondara L, Carolan H, Olson R, Schellenberg D, Germain F, Cheung A, Peacock M, Bergman $A$, Vollans $E$, Vellani $R$, McKenzie M: Volumetric radiosurgery for 1 to 10 brain metastases: A multicenter, single-arm, phase 2 study. Int J Radiat Oncol Biol Phys 94:312-321, 2016

16. Noordijk EM, Vecht CJ, Haaxma-Reiche H, Padberg GW, Voormolen JH, Hoekstra FH, Tans JT, Lambooij N, Metsaars JA, Wattendorff AR: The choice of treatment of single brain metastasis should be based on extra-cranial activity and age. Int J Radiat Oncol Biol Phys 29:711-717, 1994

17. Patchell RA, Tibbs PA, Regine WF, Dempsey RJ, Mohiuddin M, Kryscio RJ, Markesbery WR, Foon KA, Young B: Postoperative radiotherapy in the treatment of single metastases to the brain: A randomized trial. JAMA 280:1485-1489, 1998

18. Perez CA, Brady LW: Principles and Practice of Radiation Oncology, 3rd ed. Philadelphia: Lippincott-Raven, 1998: 2190

19. Phillips, TL, Scott, CB, Leibel SA, Rotman M, Weigensberg IJ: Results of a randomized comparison of radiotherapy and bromodeoxyurine to radiotherapy alone for brain metastases: Report of RTOG trial 89-05. Int J Radiat Oncol Biol Phys 30:215, 1994

20. Posner JB: Management of brain metastases. Rev Neurol 148:477-487, 1992

21. Roos DE, Wirth A, Burmeister BH, Spry NA, Drummond KJ, Beresford JA, McClure BE: Whole brain irradiation following surgery or radiosurgery for solitary brain metastases: Mature results of a prematurely closed randomized Trans-Tasman Radiation Oncology Group trial (TROG 98.05) Radiother Oncol 80:318-322, 2006

22. Smalley SR, Laws ER Jr, O'Fallon JR, Shaw EG, Schray MF: Resection for solitary brain metastasis: Role of adjuvant radiation and prognostic variables in 229 patients. J Neurosurg 77:531-540, 1992

23. Sneed PK, Suh JH, Goetsch SJ, Sanghavi SN, Chappell R, Buatti JM, Regine WF, Weltman E, King VJ, Breneman JC, Sperduto PW, Mehta MP: A multi-institutional review of radio-surgery alone vs. radiosurgery vs. radiosurgery with whole brain radiotherapy as the initial management of brain metastasis. Int J Radiat Oncol 53:519-526, 2002

24. Sperduto PW, Chao ST, Sneed PK, Luo X, Suh J, Roberge D, Bhatt A, Jensen AW, Brown PD, Shih H, Kirkpatrick J, Schwer A, Gaspar LE, Fiveash JB, Chiang V, Knisely J, Sperduto CM, Mehta M: Diagnosis-specific prognostic factors, indexes, and treatment outcomes for patients with newly diagnosed brain metastases: A multi-institutional analysis of 4,259 patients. International Journal of Radiation Oncology Biology Physics 77(3):655-661, 2010

25. Weissman DE: Glucocorticoid treatment for brain metastases and epidural spinal cord compression: A review. J Clin Oncol $6: 543-551,1988$ 